\title{
CRYSTALLIZATION KINETICS OF COCONUT OIL BASED ON GOMPERTZ MODEL
}

\author{
Mursalin $^{1,3)}$, Purwiyatno Hariyadi, ${ }^{2,3)}$, Eko Hari Purnomo ${ }^{2,3)}$, Nuri Andarwulan ${ }^{2,3)}$, and Dedi Fardiaz ${ }^{2,3)}$ \\ 1) Faculty of Agriculture Technology, Jambi University, Jalan Raya Jambi-Muara Bulian Km.15 Mendalo Darat, Jambi 36122, \\ Phone: 0741-580053, email: mursalin@unja.ac.id
}

${ }^{2)}$ Department of Food Science and Technology, Faculty of Agriculture Technology, Bogor Agricultural University, IPB Darmaga Campus, PO Box 220 Bogor 16002, Phone: 0251-8621210/8621219, Fax.0251-8623203, e-mail: fateta@ipb.ac.id.

3) Southeast Asia Food and Agriculture Science and Technology Center, Bogor Agricultural University, J1. Puspa No.1 IPB Darmaga Campus 16680, Phone/Fax: 0251-8629903, e-mail: seafast@ipb.ac.id, website: www.ipb.ac.id/seafast

\begin{abstract}
The cooling rate and temperature of crystallization has been proven to be very influential on the rate of crystal formation oil. Oil crystallization kinetics can be measured by monitoring changes in the solid fat content (SFC) of oil during cooling process. In this study, SFC measured using pulsed Nuclear Magnetic Resonance (pNMR). Four levels of cooling rates and temperature crystallization studied. Crystallization kinetics parameters were measured by applying the model of Gompertz. Gompertz model used to explain the induction time, the increase in the maximum rate of crystallization and the crystalline polymorphic. Crystallization was done by heating the oil at a temperature of $70^{\circ} \mathrm{C}$ for 10 minutes prior to rapid cooling to $29^{\circ} \mathrm{C}$. Then, rate of cooling from $29^{\circ} \mathrm{C}$ to the crystallization temperature (critical cooling rate) was set below $2^{\circ} \mathrm{C} / \mathrm{minutes}$. During the process, the oil was stirred at $15 \mathrm{rpm}$. Solid fraction was measured periodically since the crystallization temperature was reached until maximum solid fraction was achieved. The results showed that the Gompertz model able to quantitatively describe the crystallization kinetics of coconut oil. Lower critical cooling rate reduces the induction time of crystallization but accelerate the maximum increase rate of crystallization. Crystallization temperature has a negative correlation with the induction time and the maximum increase rate of crystallization. In the crystallization of coconut oil, critical cooling rate and crystallization temperature are only influence on the thermodynamics and kinetics of crystallization but not on its polymorphic formation.
\end{abstract}

Keywords - coconut oil, critical cooling rates, crystallization kinetics, gompertz model

\section{INTRODUCTION}

Crystallization kinetics is typical to each of oil and a function of the characteristics of the oil and cooling treatment applied. Crystallization kinetics parameters essential in oil include the mechanism of nucleation, crystal growth rate and induction time (time delay formation of crystals). All these kinetic parameters cannot be determined directly from the experiment, but can be extracted from the quantities generated by plotting the experimental data to the model of crystallization kinetics equation.

Crystallization kinetics was extracted by comparing mathematical model to experimental data. So far, the experimental data widely used for fitting the model is the enthalpy of crystallization kinetics measured by Differential Scanning Calorimetry (DSC) and Solid Fat Content (SFC) measured with pNMR. Models commonly used to describe kinetic of crystallization are Avrami and Gompertz model. Avrami model is suitable to describe single crystallization curves (MacNaughtan et al. 2006). Meanwhile, Gompertz model was reported producing an excellent plot for single and double crystallization curves (Kloek et al. 2000; Vanhoutte et al. 2003). Chaleepa et al. (2010) used the Gompertz model to estimate the effect of additives such as lauric acid and two types emulsifier on coconut oil.

Kinetics parameters that are important in oil crystallization are the induction time $(\tau)$, the maximum crystal growth rate $(\mu)$ and polymorphic types of crystals formed during the crystallization process. These parameters can be determined by using the Gompertz model. Gompertz equation used to describe the fat crystallisation by Kloek et al. (1998) is presented in equation (1).

$$
Y=S_{\max 2} \cdot \exp \left[-\exp \left(\frac{\mu_{2} \cdot e}{s_{\max 2}}\left(\lambda_{2}-t\right)+\right.\right.
$$$$
\text { 1)] }
$$

$\mathrm{S}_{\max 2}$ parameter associated with the maximum percentage of solid fat content measured by pNMR. Parameter $\mu_{2}(\% / \mathrm{min})$ associated with the crystal growth rate, 
while $\lambda_{2}$ (minutes) is the induction time of crystallization. Schematic illustration of Gompertz model is presented in Figure 1.

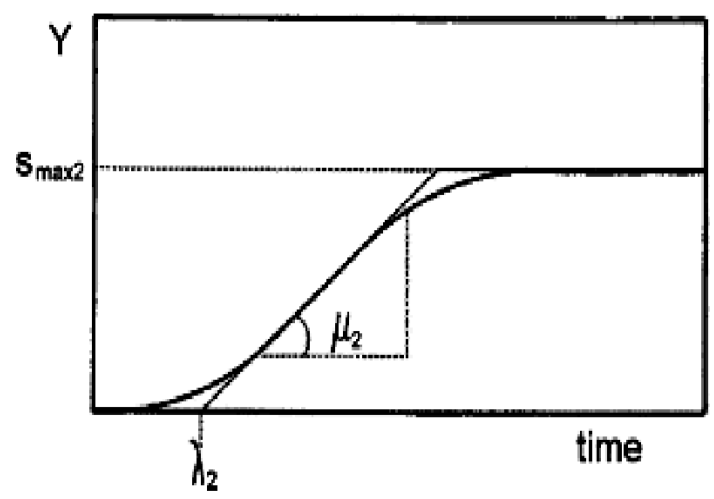

Figure 1. Illustration of parameters determination in the Gompertz model (Kloek et al. 1998).

In this study, based on changes in the amount of solid fraction (SFC) of oil, the effect of critical cooling rate and crystallization temperature of coconut oil is presented. Therefore, coconut oil cooled in three stages of cooling which are the initial cooling (temperature of $70-29{ }^{\circ} \mathrm{C}$ ), the critical cooling (from $29{ }^{\circ} \mathrm{C}$ to the specified crystallization temperature), and cooling to maintain a constant oil temperature at the specified crystallization temperature (Mursalin et al. 2013).

This study is aimed to determine the effect of the critical cooling rate and crystallization temperature on the crystallization kinetics of coconut oil. The Gompertz equation is used to extract kinetic parameters associated with the nucleation mechanism, induction time, the maximum crystal growth rate and type of formed polymorphism crystals.

\section{MAterial AND Methods}

The main materials used in this study are refined bleached deodorized coconut oil (RBDCNO) obtained from PT BARCO, Jakarta. A total of $3 \mathrm{ml}$ sample was placed in a NMR tube to be analyzed for its solid fraction changes during the crystallization process. Crystallization method applied to the sample has been modified from Zaliha et al. (2004), Chaleepa et al. (2010) and exactly as was done by Mursalin et al. (2016). Prior to cooling, oil was heated at $70{ }^{\circ} \mathrm{C}$ for 10 minutes to remove crystals that may still exist and erasing memory previously heated or cooled (rejuvenation). After that, from $70-29^{\circ} \mathrm{C}$, the oil has been rapid cooled. Then a rate of cooling from $29^{\circ} \mathrm{C}$ to the crystallization temperature (critical cooling rate) was set below $2{ }^{\circ} \mathrm{C} /$ minutes. During the process, the oil was stirred at $15 \mathrm{rpm}$. After the crystallization temperature reached, the oil temperature kept constant until the end of the crystallization process. Schematic illustration of crystallization method is presented in Figure 2.

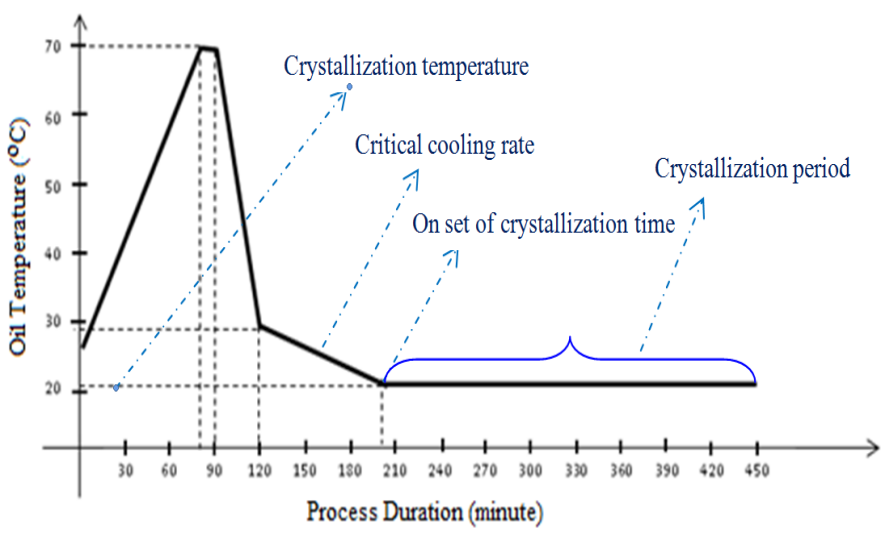

Figure 2. Scheme of crystallization method on coconut oil dry fractionation

(Mursalin et al., 2016)

Observation on solid fraction in the oil during crystallization periodically conducted since the crystallization temperature was reached to a maximum solid fraction was measured (relatively constant for the last 3 measurements). Heating and cooling oil is controlled using waterbath. Analysis of solid fraction in the oil is carried out using Bruker Minispec PC 100 NMR Analyzer. NMR is calibrated using standard solid fraction $0 \%, 31.5 \%$ and $72.9 \%$.

Gompertz model to be used in this study can be written as follows:

$$
F(t)=A e^{-e^{((\mu e(\tau-t) / A+1)}}
$$

Where $F(t)$ is the value percentage of solid fraction crystallized at time $t, A$ is the maximum solid fraction in percent, $\mu$ is the maximum crystallization rate of increase (tangent value of the inflection point from crystallization curve) and $\tau$ is the induction time (intercept value from tangent at inflection point with the $\mathrm{x}$-axis in the form of time). Value of $F(t)$ is calculated according to the equation:

$$
F(t)=\frac{S F_{t}}{S F \text { maximum }} \times 100 \%
$$

Where $\mathrm{SF}_{\mathrm{t}}$ is solid fraction of oil at $\mathrm{t}$ time and the maximum $\mathrm{SF}$ is the maximum solid fat content can be generated from the process of crystallization at a certain temperature and cooling rate. Induction time of nucleation and maximum crystallization growth rate can be obtained by comparing the observed data with the Gompertz model.

\section{RESULT AND DISCUSSION}

Plot obtained from fitting SFC observation data as a function of cooling time with Gompertz equation, $F(t)=$ $\mathrm{Ae}^{-\left(\left(\frac{\mu \mathrm{e}(\tau-\mathrm{t})}{\mathrm{A}}\right)+1\right)}$, shows that the model quantitatively describes the experimental data (Figure 3). Induction time or lag phase of crystal growth, $(\tau, \mathrm{min})$, strongly affected by the critical cooling rate $\left(\mathrm{v}_{\mathrm{c}},{ }^{\circ} \mathrm{C} / \mathrm{min}\right)$. The higher critical cooling rate results in greater induction time as indicated by the shifted of the curve to the right, (Figure $3 \mathrm{a}$ ). The effect shown by the 
crystallization temperature $\left(\mathrm{T}_{\mathrm{cr}},{ }^{\circ} \mathrm{C}\right)$ is the opposite to that shown by the critical cooling rate (Figure $3 \mathrm{~b}$ and Table 1 ).
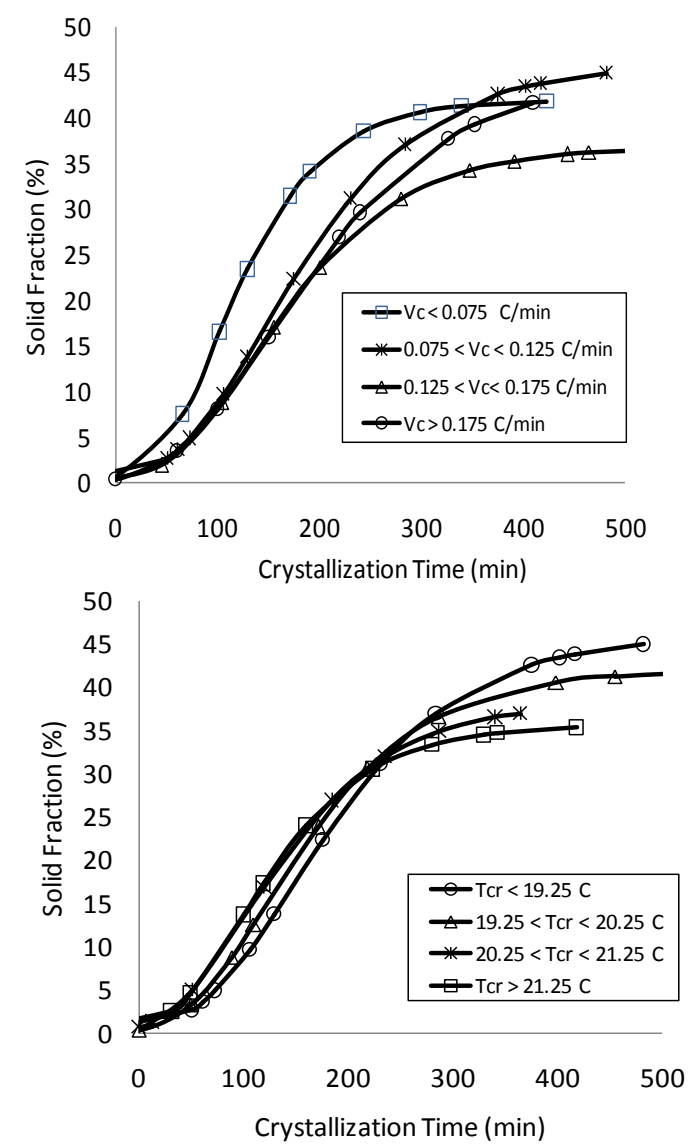

(a)

(b)

Figure 3. Plot the experiments results with the Gompertz equation on four critical cooling rate (a) and four different crystallization temperatures (b) coconut oil; $\mathrm{v}_{\mathrm{c}}=$ critical cooling rate; $\mathrm{T}_{\mathrm{Cr}}=$ crystallization temperature

Induction time showed crystal nuclei developmental delays into crystals with larger size (Kloek et al. 2000; Vanhoutte et al. (2002). Increase of the induction time is in line with the increase of critical cooling rate. This condition indicates that increase in the critical cooling rate caused a delay of crystallization. Nucleation is not immediately followed by its growth into larger crystals. This also means that an increase in the critical cooling rate on coconut oil crystallization causes an increase in the lag time for crystal growth.
Table 1. Crystallization induction time of coconut oil at different treatment of critical cooling rate and crystallization temperature

Treatment

Induction time

Critical cooling rate $\left({ }^{\circ} \mathrm{C} / \mathrm{min}\right)$

- $\mathrm{v}_{\mathrm{c}}<0.075$

- $\quad 0.075<\mathrm{v}_{\mathrm{c}}<0.125$

$30.97 \pm$

- $0.125<\mathrm{v}_{\mathrm{c}}<0.175$

- $\mathrm{V}_{\mathrm{c}}>0.176$

Crystallization temperature $\left({ }^{\circ} \mathrm{C}\right)$

- $\mathrm{T}_{\mathrm{cr}}<19.25$

- $19.25<\mathrm{T}_{\mathrm{cr}}<20.25$

- $20.25<\mathrm{T}_{\mathrm{cr}}<21.25$

$20.81 \pm$

- $\mathrm{T}_{\mathrm{cr}}>21.25$

$26.59 \pm$

Further analysis of the results showed that an increase in the critical cooling rate leads to an increase in the induction time of coconut oil in polynomial (quadratic) form (Figure 4a) and an increase in crystallization temperature will decrease induction time is polynomial (quadratic) as shown in Figure $4 \mathrm{~b}$. The relationship between the critical cooling rate with induction time can be described by $\tau=1931 . \mathrm{v}_{\mathrm{c}}^{2}-318.2 \mathrm{v}_{\mathrm{c}}+38.01$. The relationship between the temperature of crystallization induction time can be described as $\tau=4.568 \mathrm{~T}_{\mathrm{Cr}}{ }^{2}-191.8 \mathrm{~T}_{\mathrm{Cr}}+$ 2035. 

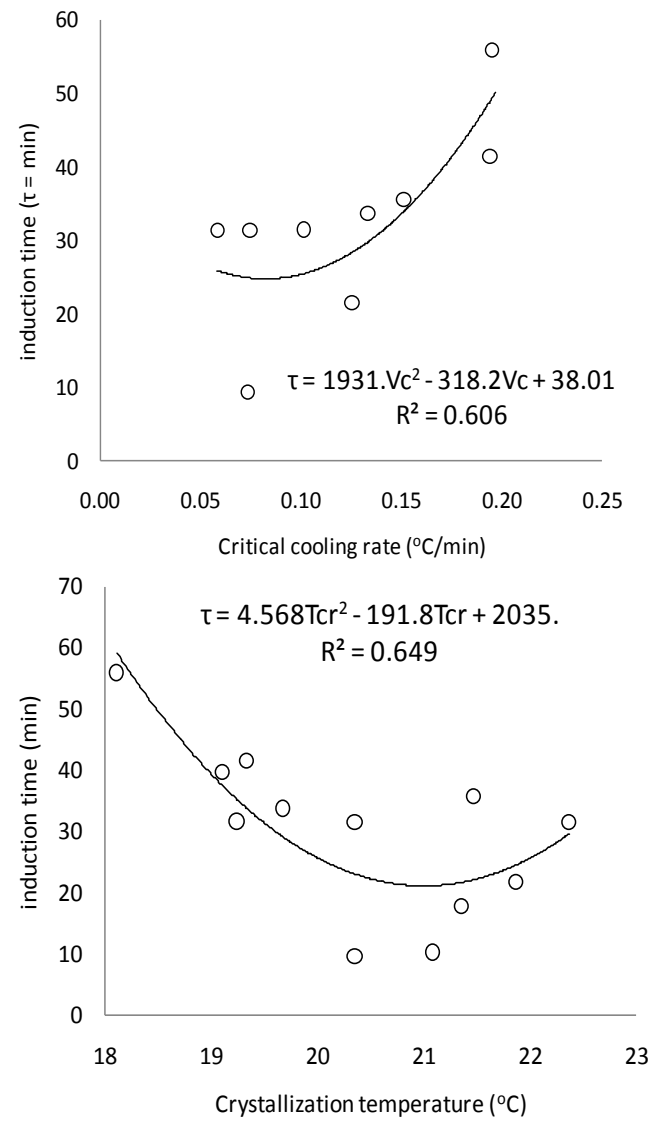

(a)

(b)

Figure 4. Relationship between the induction time with the critical cooling rate (a) and crystallization temperature $(\mathrm{b}) ; \mathrm{v}_{\mathrm{c}}=$ critical cooling rate; $\mathrm{T}_{\mathrm{Cr}}=$ crystallization temperature; $\tau=$ induction time

In Figure $4 \mathrm{a}$, it can be observed that slower temperature decrease in the second cooling phase (smaller critical cooling rate) causes a shorter $\tau$. According to Arnaud et al. (2007), at the slower cooling rate, TAG had enough time to interact. In contrast to the rapid cooling rate, TAG did not have enough time to organize itself in a more stable conformation.

Figure $4 \mathrm{~b}$ shows that at the crystallization temperature interval $18.0-22.0{ }^{\circ} \mathrm{C}$, increasing the crystallization temperature decreases the induction time of crystallization. It means that at the greater crystallization temperature, crystallization induction time is shorter. In general, an isothermal condition in the $\mathrm{TCr}$ with a low degree of supercooling accelerates the occurrence of crystallization, indicated by a shorter $\tau$. This is in agreement with the observation of Timms (2005) which revealed that the high supercooling (low crystallization temperature) causes an increase in the nucleation rate (formation of crystal nuclei) and oil viscosity so it delay the merging process of the nuclei.

Effect of critical cooling rate and crystallization temperature to maximum crystal growth rate can be seen in Figure 5.
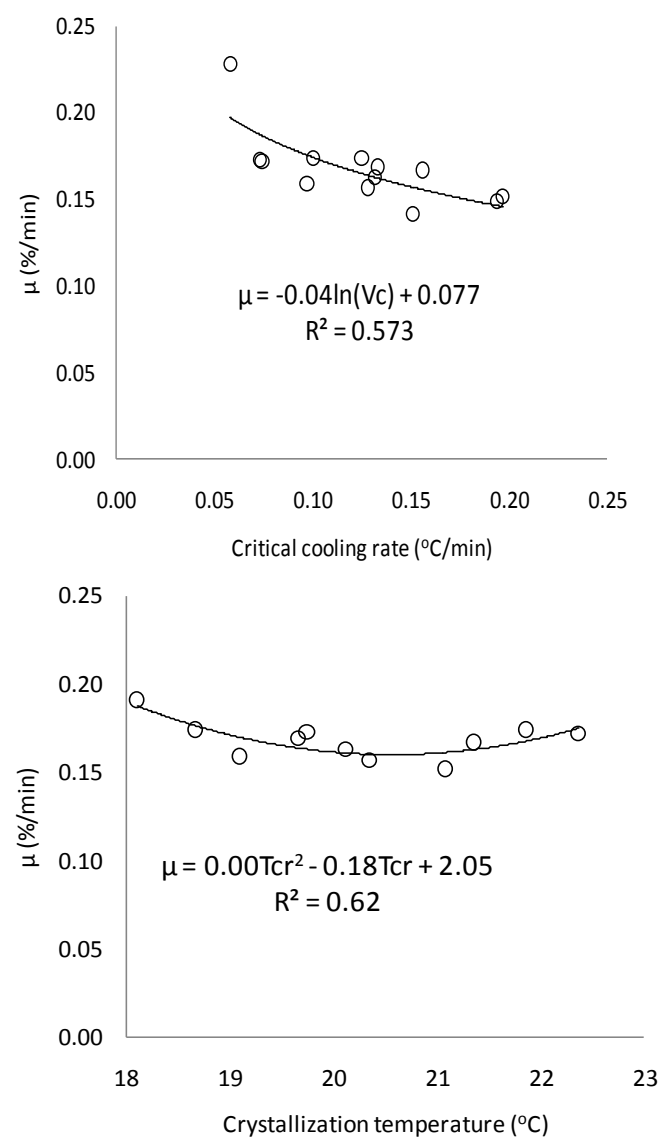

(a)

(b)

Figure 5 Relationship between maximum rate of crystal growth with critical cooling rate (a) and crystallization temperature (b); $\mathrm{v}_{\mathrm{c}}=$ critical cooling rate; $\mathrm{T}_{\mathrm{Cr}}=$ crystallization temperature; $\mu$ maximum rate of crystal growth

Figure 5 shows that $\mu$ of coconut oil during the crystallization process logarithmically decreased when the $\mathrm{v}_{\mathrm{c}}$ is increased, the relationship between $v_{c}$ and $\mu$ can be described by the equation $\mu=-0.04 \ln \left(v_{c}\right)+0.077$ (Figure 5a). At the studied crystallization temperature interval, $\mathrm{T}_{\mathrm{Cr}}$ increase was followed by an increase of $\mu$. Correlation between $\mathrm{T}_{\mathrm{Cr}}$ and $\mu$ of coconut oil at $18-22{ }^{\circ} \mathrm{C}$ temperature interval can be described by the equation $\mu=0.00 \mathrm{Tcr}^{2}-0.18 \mathrm{Tcr}+2.05$ (Figure 5b).

According to Arnaud et al. (2007), an increase in $\mu$ samples during crystallization can be attributed to the increased number of fat crystals formed as well as the degree changes of crystalline that occurred. According to Timms (2005) an increase in $\mu$ is characterized by an increase in the solid amount in the liquid phase of the oil, which is influenced by the crystal size distribution of fat and the interaction that occurs between the crystals. The aggregated crystals tend to form voluminous aggregates with volume greater than total volume of the primary crystals, which finally leads to an increase the solid fraction. Hence, low $\mu$ shows oil crystal did not develop or did not occurs formation of secondary crystals or aggregates which is a combination of crystalline nuclei. 
There is a strong correlation between crystallization induction times with $\mu$. An increase in $\mu$ does not suddently occur after $\mathrm{T}_{\mathrm{Cr}}$ isothermal achieved, as indicated by the SFC baseline plot which is still flat until a certain period of time. If at any point SFC drastically changes from the baseline, according to Chen et al. (2002), the point reflected the occurance of crystallization induction time, and improvement degree of SFC after that point illustrates the amount of $\mu$.

At low $v_{c}, \mu$ has a high value. This is in line with the research results of Arnaud et al. (2007) which revealed that, at a slow cooling rate, TAG has enough time to interact each other. In contrast to the rapid cooling rate, TAG did not have enough time to organize itself in a more stable conformation so that the rate of crystal growth is impaired and the formation of the primary nuclei continues. As the result, small crystals at the end of the process were obtained.

At low $\mathrm{T}_{\mathrm{Cr}}$ value $\mu$ is also low. This is in accordance with the research results of De-Graef et al. (2007) where $\mu$ rapidly increases and reaches a higher value when lower $\mathrm{T}_{\mathrm{Cr}}$ is applied. This is because it is associated with the occurrence of supercooling condition. The larger condition of supercooling (at the lower crystallization temperature) provides higher driving force of crystallization. Therefore, at the lower $\mathrm{T}_{\mathrm{Cr}}$ crystallization process occurs faster.

Polymorphic form of TAG which crystallized refers to the ability of the molecules arrange themselves in a crystal lattice packed in a special form (Chen et al., 2002; Timms 2005). Logarithmic plot of the induction time as a function of the crystallization temperature, called as nucleation curve, can be used to predict the polymorphisms type that occur (Timms 1984, Ng 1990; Chen et al. 2002; Chaleepa et al. 2010). In this study, the nucleation curve will be used to predict the influence of four intervals of critical cooling rate to the polymorphisms occured in coconut oil. Nucleation curve of coconut oil as a function of critical cooling rate at 18.0-22.0 ${ }^{\circ} \mathrm{C}$ temperature intervals was presented in Figure 6.

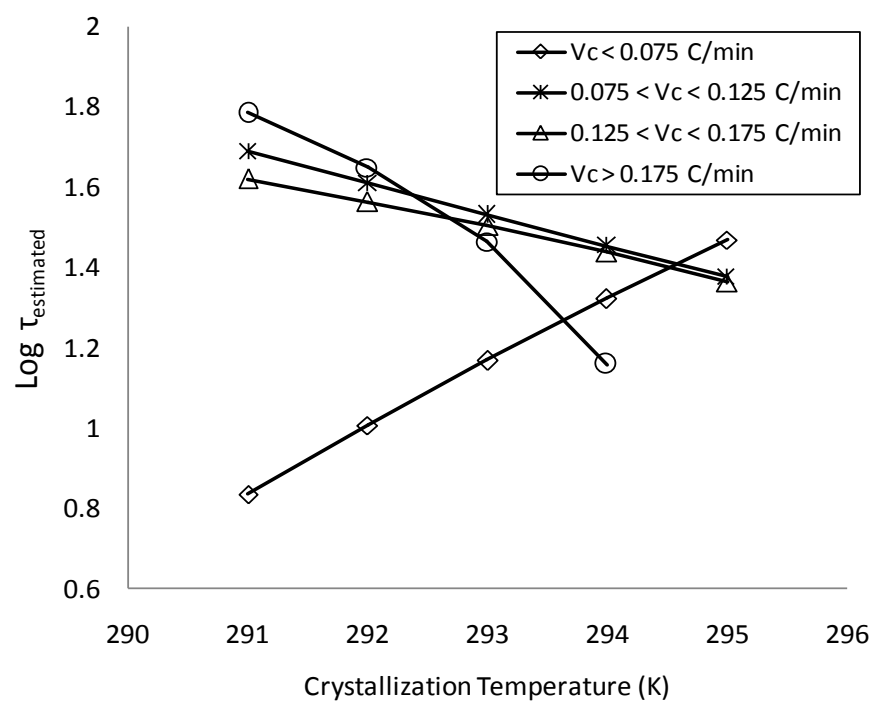

Figure 6. Nucleation curve of coconut oil
Figure 6 shows nucleation curve of coconut oil is continuous without jumping on the induction time. The crystallization behavior can be interpreted that during the process of crystallization at various critical cooling rate and crystallization temperature, coconut oil only formed one type of polymorphic crystal. This is in line with that reported by Chaleepa et al. 2010 which says that the crystallization of coconut oil is always in the polymorphic form $\beta^{\prime}$. This indicates that the critical cooling rate only affects the thermodynamics and kinetics of crystallization on coconut oil but has no effect on the polymorphism formation.

\section{CONCLUSION}

Gompertz model is good to be used for describing the crystallization kinetics of coconut oil based on changes of oil solid fat content during the crystallization process. The model has the adjustability of more than $99 \%$ with the experimental results in this study.

A low critical cooling rate produces induction time were also lower but will produce high content of maximum solid fat, and high rate of maximum crystal growth. Coconut oil crystallization temperature has negative correlation with the maximum SFC, induction time, and the maximum increase rate in crystallization.

Critical cooling rate and crystallization temperature only affected thermodynamics and kinetics of coconut oil crystallization; however have no effects to the polymorphism formation.

\section{REFERENCES}

Arnaud E, M Pina, A Collignan. 2007. Suitable cooling program for chicken fat dry fractionation. Eur J Lipid Sci Technol, 109:127-133.

Chaleepa K, Szepes A, Ulrich J. 2010. Effect of additives on isothermal crystallization kinetics and physical characteristics of coconut oil. Chemistri and Physic of Lipids, 163:390-396. DOI:10.1016/j.chemphyslip.2010.03.005

Chen CW, OM Lai, HM Ghazali, CL Chong. 2002. Isothermal crystallization kinetics of refined palm oil. $\mathrm{J} \mathrm{Am} \mathrm{Oil}$ Chem Soc 79, 403-410.

De Graef V, I Foubert, KW Smith, FW Cain, K Dewettinck. 2007. Crystallization behavior and texture of transcontaining and trans-free palm oil based confectionery fats. J Agric Food Chem, 55: 1025810265 .

Kloek W. 1998. Mechanical properties of fats in relation to their crystallization. $[P h D$ Thesis], Wageningen Agricultural University, the Netherlands.

Kloek W, P Walstra, TV Vliet. 2000. Crystallization kinetics of fully hydrogenated palm oil in sunflower oil mixtures. J Am Oil Chem Soc, 77: 389-398. 
MacNaughtan W, IA Farhat, C Himawan, VM Starov, AGF Stapley. 2006. A Differential scanning calorimetry study of the crystallization kinetics of tristearintripalmitin mixtures. J Am Oil Chem Soc, 83: 1-9.

Mursalin, P Hariyadi, EH Purnomo, N Andarwulan, D Fardiaz, 2013. Dry fractionation of coconut oil using $120 \mathrm{~kg}$-scale crystallizer to produce concentrated medium chain triglycerides. $J$ Industrial Crops Research (LITTRI), 19: 41-49.

Mursalin, P Hariyadi, EH Purnomo, N Andarwulan, D Fardiaz, 2016. Crystallization kinetics of coconut oil based on Avrami model. International Food Research Journal 23(4): 1355-1360.

$\mathrm{Ng}$ WL. 1990. A study of the kinetics of nucleation in a palm oil melt. J Am Oil Chem Soc, 67: 879-882.

Timms RE. 1984. Phase behavior of fats and their mixtures. Prog Lipid Res, 23: 1-38.

Timms RE. 2005. Fractional crystallisation - the fat modification process for $21^{\text {st }}$ century. Eur J Lipid Sci Technol, 107: 48-57.

Vanhoutte B, K Dewettinck, I Foubert, B Vanlerberghe, A Huyghebaert. 2002. The effect of phospholipids and water on the isothermal crystallization of milkfat. Eur J Lipid Sci Technol, 104: 490-495.

Vanhoutte B, K Dewettinck, B Vanlerberghe, A Huyghebaert. 2003. Monitoring milk fat fractionation: filtration properties and crystallization kinetics. $J \mathrm{Am}$ Oil Chem Soc, 80: 213-218.

Zaliha O, CL Chong, CS Cheow, AR Norizzah, MJ Kellens. 2004. Crystallization properties of palm oil by dry fractionation. $J$ Food Chem 86: 245-250. DOI: 10.1016/j.foodchem.2003.09.032. 